\title{
KOREOGRAFI TARI EMUN BERERENG KARYA MUKHLIS GAYO DI ACEH TENGAH
}

\author{
DEDEK
}

Prodi Pendidikan Tari

\begin{abstract}
The theory used in this research is the theory Koreeografi of Sudarsono. When the study to discuss Emun Berereng dance performed during 2 months, ie from the beginning of October 2015 to December 2015. The study Desa Blang Kolak II District Bebesen Central Aceh district. The population is a resource, artists, traditional leaders and dancers who know about dance Gayo especially dance Emun Berereng in Central Aceh, the sample in this study were numbered four persons namely speakers, traditional leaders, artists and dancers dance Emun Berereng in Aceh Central. Data collection techniques include literature study, observation, Interview, and documentation, which is then analyzed by qualitative descriptive method.

Based on research done that dance Emun Berereng have a soft form of motion, the design contained on the dance floor Emun berereng is catastrophically, split, alternately and interchangeably. Top design contained in this dance is the design on a flat, contrast, vertical, medium, low, and high pending. Dance wear Emun Berereng external musical accompaniment accompaniment yaiu born noise generated by devices outside the human body like a drum, flute, harp and other musical instruments. The themes contained in this dance is how the relationship young people gayo in mengespresikan feelings of love towards people in sukain in ancient times, Clothing used in dance Berereng Emun this is a long-sleeved shirt filigree headdress that had been in kreasikan (headscarf). Property used in dance Emun Berereng is scarves.
\end{abstract}

Keywords: Choreography Emun Berereng work Muklis Gayo, in Central Aceh. 


\section{PENDAHULUAN}

Aceh sebelumnya pernah disebut dengan sebutan Daerah Istimewa Aceh pada tahun 19592001, dan Nanggroe Aceh Darussalam pada tahun 2001-2009. Aceh adalah provinsi paling barat di Indonesia dengan Ibu Kota Banda Aceh. Aceh memiliki otonomi yang teratur tersendiri, disebabkan Aceh berbeda dengan kebanyakan provinsi di Indonesia. Aceh berbatasan dengan Teluk Benggala di sebelah utara, Samudera Hindia di sebelah barat, Selat Malaka di sebelah timur, dan Sumatera Utara di sebelah tenggara dan selatan. Suku bangsa yang mendiami Aceh merupakan keturunan orang-orang Melayu dan Timur Tengah yang menyebabkan wajah-wajah orang Aceh berbeda dengan orang Indonesia pada umumnya. Sebagian besar masyarakat Aceh bermata pencarian sebagai petani namun tidak sedikit juga yang pedagang.

Aceh memiliki budaya yang unik dan beraneka ragam yang dipengaruhi oleh budaya-budaya Melayu dan Timur Tengah. Bentuk kesenian yang terkenal di Aceh antara lain Seudati, Seudati Inong, dan Seudati Tunang., Kaligrafi Arab, Hikayat Perang Sabil.

Aceh terbagi atas 23 Kabupaten, salah satu diantaranya adalah Kabupaten Aceh Tengah. Aceh Tengah berdiri tanggal 14 April 1948 berdasarkan UndangUndang No. 10 tahun 1948 dan dikukuhkan kembali sebagai sebuah kabupaten pada tanggal 14 November 1956 melalui Undangundang No. 7 (Drt) tahun 1956.
Kemudian, pada 7 Januari 2004, Kabupaten Aceh Tengah kembali dimekarkan menjadi Kabupaten Aceh Tengah dan Bener Meriah dengan Undang -undang No. 41 tahun 2003. Kabupaten Aceh Tengah beribukota di Takengon, sementara Kabupaten Bener Meriah beribukota Simpang Tiga Redelong.

Tari Emun Berereng yang merupakan salah satu tari dari daerah Aceh Tengah mengandung nilai budaya masyarakat Gayo yang menggambarkan cerita cinta pada zaman dahulu. Cerita cinta pada masyarakat Gayo dulunya masih menjunjung adat yang tinggi, sehingga tidak berani berbicara secara langsung apalagi bertatap muka hanya melihat dari kejauhan dan menandai orang yang di sukai contohnya seperti menandai sanggulnya, dimana tempat tinggalnya, itu semua di lakukan oleh perantara yang di tunjuk mereka. Tari ini terdapat syair yang dilantunkan seiring dengan musik iringan pada tari Emun Berereng ini. Tari Emun Berereng di ciptakan oleh Mukhlis Gayo pada tahun 1972 dan pencipta syair adalah Ibrahim Kadir, yang menceritakan kisah cinta. Emun Berereng dapat di tampilkan pada setiap kesempatan yaitu pada saat keramaian dan kegembiraan yang sifatnya menghibur. Tidak terkait dengan adanya peristiwa atau upacara-upacara tertentu.

Muklis Gayo merupakan seorang budayawan di daerah Takengon (Aceh Tengah) beliau lahir pada 30 Mei 1954 di Takengon. Menempuh pendidikan dari SD sampai dengan SMA di Takengon. 
Dan melanjutkan S1 Ilmu Hukum di Unuversitas 17 Agustus 1945 di Jakarta. Beliau pernah bekerja sebagai pegawai Sekretariat Negara RI, Unit BINA GRAHA/SETDALOPBANG 1981 s.d 2009. Beliau juga pernah menjadi staf ahli bidang hukum tahun 20082009, dan sekarang beliau menjabat sebagai kepala Dinas Pariwisata Pemuda dan Olahraga Aceh Tengah, 2009 sampai dengan sekarang (wawacara langsung dengan narasumber).

Tari Emun Berereng ini memiliki gerak yang sederhana dan berpijak dari gerak tradisi yang dikembangkan. Selain itu juga dilihat dari sudut pandang koreografi, tari Emun Berereng memiliki perbedaan dalam langkah gerak kaki, garis edar yang dilalui oleh masing-masing penari dan ruang dari gerak tangan yang lebih luas maupun desaindesain yang ditimbulkan jika dibandingkan dengan tarian yang ada di Gayo.

Berdasarkan latar belakang masalah, indentifikasi masalah dan pembatasan masalah, maka permasalahan dapat di rumuskan sebagai berikut: "Bagaimana Koreografi Tari Emun Berereng Karya Muklis Gayo di Aceh Tengah". Tujuan penelitian ini adalah Mendeskripsikan koreografi tari Emun Berereng karya Muklis Gayo di Aceh Tengah. Penelitian ini diharapkan dapat bermanfaat sebagai bahan referensi untuk menjadi acuan pada penelitian yang relevan, bahan motivasi bagi setiap pembaca, khususnya generasi muda masyarakat Gayo di kabupaten Aceh Tengah untuk menindaklanjuti atau melestarikan seni tari Emun
Berereng, menunjukkan bahwa tari Emun Berereng mempunyai nilainilai bagi masyarakat Gayo di kabupaten Aceh Tengah.

\section{LANDASAN TEORITIS DAN KERANGKA KONSEPTUAL}

Landasan teoritis merupakan suatu acuan atau pedoman berfikir dalam menyelesaikan masalah suatu penelitian. Dalam penelitian ini penulis membuat landasan teoritis berdasarkan analisis kepustakaan yang berhubungan dengan masalah pokok yang akan di teliti.

Menurut Y. Sumandiyo Hadi dalam bukunya yang berjudul "Koreografi"(2012:1) menjelaskan bahwa istilah koreografi berasal dari kata Yunani "choreia' yang berarti tari massal atau kelosmpok dan kata 'grapho'yang berarti catatan. Jadi secrara harfiah artinya catatan tetntang tari.

Menurut Sal Mugiyanto dalam “Koreografi"(1983:3-4) menjelaskan secara rinci mengenai koreografi yaitu 'dalam dunia tari dewasa ini, koreografi lebih diartikan sebagai pengetahuan penyusun tari, sedangkan seniman atau penyusunnya dikenal dengan nama koreografer, yang dalam bahasa kita sekarang dikenal sebagai penata tari “.

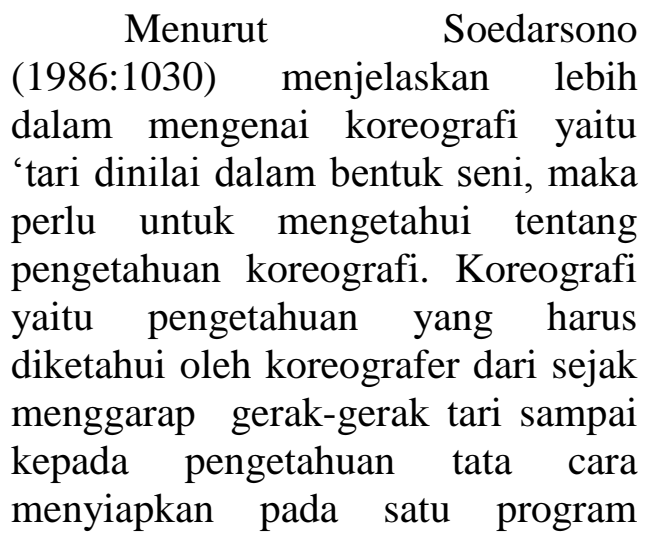


pertunjukan. Koreografi yang didalamnya adalah gerak, desain lantai, desain atas, musik, desain dramatik, dinamika, desain kelompok, tema rias, kostum dan property tari".

Kerangka konseptual dari kajian mengenai Emun Bereng pada masyarakat Gayo di aceh Tengah akan mengulas dalam teori dari Y. Sumandiyo yang isinya gerak, ruang dan waktu serta teori koreografi dari Soedarsono yang isinya elemenelemen dalam komposisi tari itu adalah gerak, desain lantai, desain atas, musik, desain dramatik, dinamika, desain kelompok, tema, rias, kostum dan propeti. Hal ini yng akan dikaji oleh penulis sehingga dapat memberikan sumbangaan terhadap masyarakat Gayo serta peneliti-peneliti yang membuat tentang tari dari daerah Gayo.

\section{PETA KERANGKA KONSEP}

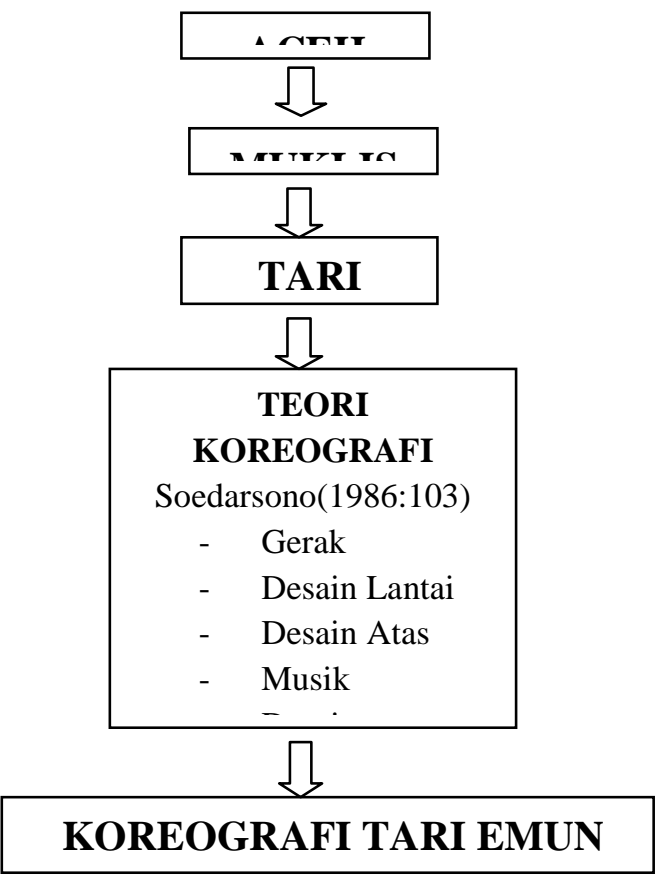

\section{METODOLOGI PENELITIAN}

Dalam penelitian ini penulis dengan menggunakan metode penelitian kualitatif yang bersifat deskriptif, karena memberikan keterangan yang aktual dan jelas sesuai dengan yang dibutuhkan dalam penelitian ini. Menurut Suwardi Endraswara (2006 : 6) mengatakan bahwa: " penelitian budaya memang melekat dengan penelitian kualitatif. Jika kualitatif boleh dipandang sebagai perspektif penelitian, berarti penelitian budaya banyak memanfaatkan perspektif kualitatif. Hal ini tidak berarti bahwa penelitian budaya alergi pada perspektif kuantitaf. Namun, mencermati fenomena budaya yang dinamis, memang dipandang cocok jika menggunaka perspektif kualitatif".

Dari pendapat tersebut dapat dikatakan bahwa pelaksanaan deskriptif kualitatif tidak terbatas pada pengumpulan data dan penyusunan data, tetapi meliputi analis dan interprestasi data-data yaitu bagaimana Bentuk Koreografi tari Emun Berereng pada masyarakat Gayo di Bebesen kabupaten Aceh tengah.

Lokasi penelitian yang dipilih untuk mengadakan penelitian ini yaitu di Desa Blang Kolak II Kecamatan Bebesen Kabupaten Aceh Tengah yang merupakan tempat menggali data-data atau sumber mengenai tari Emun Berereng.

Populasi dalam penelitian merupakan hal yang sangat penting untuk menentukan beberapa jumlah populasi sesuai dengan data yang akan dikumpulkan. Populasi adalah wilayah generalisasi yang terdiri atas 
objek (tarian yang akan diteliti) atau subjek (masyarakat) yang mempunyai kualitas dan karakteristik tertentu yang ditetapkan oleh peneliti untuk dipelajari dan kemudian ditarik kesimpulannya (Sugiyono, 2010:215).

\section{Sugiyono}

menyatakan bahwa, "sampel adalah bagian dari jumlah dan karateristik yang dimiliki oleh pipulasi tersebut". Berdasarkan pernyataan tersebut sampel dalam penelitian ini adalah tokoh adat dan seniman Gayo yang mengetahui tentang tari Emun Berereng.

Sugiyono(2010:224), mengatakan bahwa: "teknik pengumpulan data merupakan langkah yang paling strategis dalam penelitian, karena tujuan utama dari penelitian adalah mendapatkan data. Tanpa mengetahui teknik pengumpulan data, maka penelitian tidak akan mendapatkan data yang memenuhi standar data yang ditetapkan".

Sutrisno Hadi (Sugiyono, 2010:145) mengemukakan bahwa: "observasi merupakan suatu proses yang kompleks, suatu proses yang tersusun dari berbagai proses biologis dan psikologis. Dua diantara yang terpenting adalah proses-proses pengamatan dan ingatan. Berdasarkan pendapat diatas maka pelaksanaan penelitian yang dilakukan dilapangan adalah dengan pengamatan terlibat agar penulis di dapat mengamati serta memahami Eksistensi dan musik iringan tari Emun Berereng pada masyarakat Gayo.

\section{PEMBAHASAN}

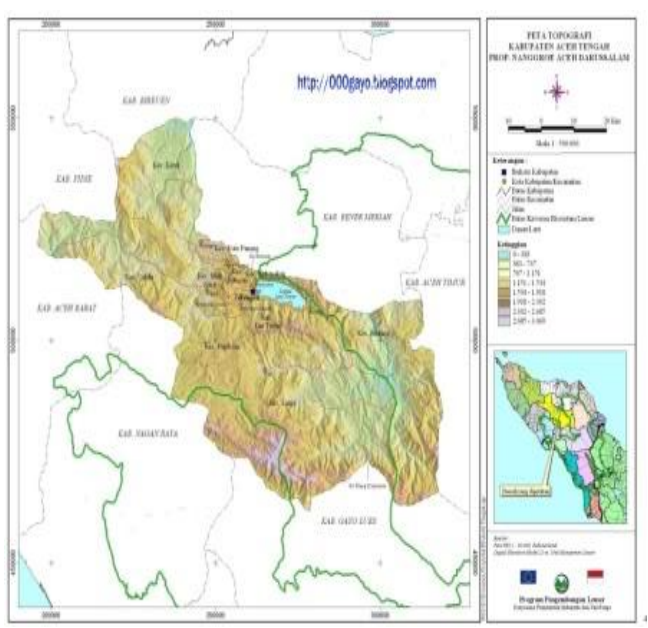

Peta Kabupaten Aceh Tengah

$\begin{array}{lr}\text { Kabupaten Aceh } & \text { Tengah } \\ \text { memiliki topografi } & \text { wilayah } \\ \text { bergunung dan berbukit dengan } \\ \text { ketinggian rata-rata bervariasi antara }\end{array}$ $200-2.600$ meter diatas permukaan laut. Penggunaan lahannya didominasi oleh kawasan hutan seluas $280.647 \mathrm{Ha}$ atau 64,98\% dari luas wilayah, dan sisanya berupa tanah bangunan, sawah, tegal/ kebun, lading/huma, padang rumput, rawarawa, kolam, tambak, perkebunan dan areal peruntukan lainnya. Sesuai dengan letak geografisnya, iklimnya termasuk iklim equatorial, dengan jumlah hari hujan rata-rata 137 hari/ tahun dan curah hujan rata-rata 1.822 $\mathrm{m} /$ tahun. Suhu udara rata-rata berkisar pada 20 derajat celcius dengan kelembaban nisbi antara 80 $84 \%$.

Kabupaten Aceh Tengah berdiri pada tanggal 14 April 1948 berdasarkan Undang-Undang No. 10 tahun 1948 dan dikukuhkan kembali sebagai sebuah Kabupaten pada tanggal 14 November 1956 melalui Undang-Undang No. 7 tahun 1956. 
Wilayahnya meliputi tiga kewedanaan yaitu kewedanaan Takengon, Gayo Lues dan Tanah Alas. Kemudian pada tahun 1974 Kabupaten Aceh Tengah dimekarkan kembali menjadi Kabupaten Aceh Tengah dan Aceh Tenggara melalui Undang-undang No. 4 Tahun 1974, pemekeran ini terjadi karena sulitnya transportasi dan didukung oleh masyarakat . Pada tanggal 7 Januari 2004 berdasrkan Undang-undang No. 41 Tahun 2003 Kabupaten Aceh Tengah kembali mengalami pemekaran menjadi 2 kabupaten yakni Kabupaten Aceh Tengah dengan ibukota Takengon dan Kabupaten Bener Meriah dengan ibukota Simpang Tiga Redelong

Gayo adalah orang-orang yang mendiami kabupaten yang disebut Aceh Tengah dan Bener Meriah. Penduduk daerah Gayo pada masa sekarang ini terdiri dari suku bangsa Gayo sendiri, yang juga berasal dari suku bangsa lain seperti Aceh, Jawa, Minangkabau bahkan orang-orang Cina, baik WNI maupun WNA yang menetap di Takengon.

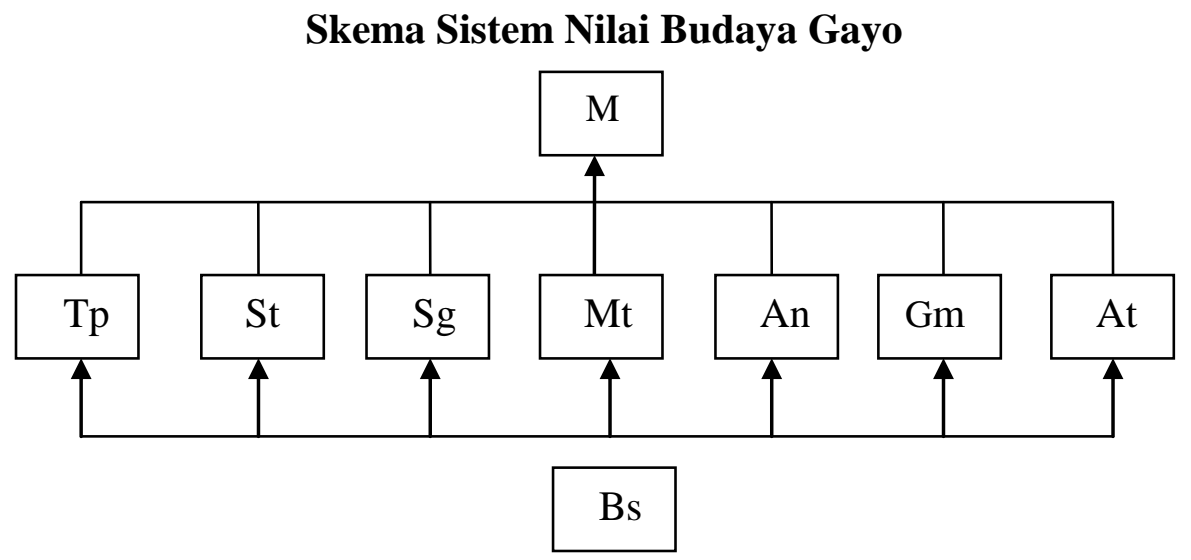

Sistem Nilai Budaya Gayo

Keterangan:

$\mathrm{M}:$ mukemel ( harga diri )

Tp : tertip (tertib)

St : setie (setia)

$\mathrm{Sg}$ : semayang Gemasih (kasih sayang )

Mt : mutentu (kerja keras)

An : amanah (amanah)

Gm : genap mupakat (musyawarah)

At : alang tulung (tolong menolong)

Bs : bersikemelen ( kompetitif)

Tari Emun Berereng yang merupakan salah satu tari dari daerah
Aceh Tengah mengandung nilai budaya masyarakat gayo yang menggambarkan cerita cinta pada zaman dahulu. Cerita cinta pada masyarakat Gayo dulunya masih menjunjung adat yang tinggi, sehingga tidak berani berbicara secara langsung apalagi bertatap muka hanya melihat dari kejauhan dan menandai orang yang di sukai contohnya seperti menandai sanggulnya, dimana tempat tinggalnya, itu semua di lakukan oleh perantara yang di tunjuk mereka. 
Tari ini terdapat syair yang dilantunkan seiring dengan musik iringan pada tari Emun Berereng ini. Tari Emun Berereng di ciptakan oleh Mukhlis Gayo pada tahun 1972. Mukhlis Gayo merupakan seniman Aceh Tengah (Takengon) yang telah banyak menciptakan tari diantaranya Guru Didong, Peteri Bensu, Resam Berume dan Emun Berereng. Pencipta syair dalam tari ini adalah Ibrahim Kadir, yang menceritakan kisah cinta. Emun Berereng dapat di tampilkan pada setiap kesempatan yaitu pada saat keramaian dan kegembiraan yang sifatnya menghibur. Tidak terkait dengan adanya peristiwa atau upacaraupacara tertentu.

Tari Emun Berereng terdapat beberapa motif gerak akan dirangkai menjadi ragam gerak. Gerak tangan dan kaki disesuaikan dengan isi syair yang menceritakan tentang kegiatankegiatan yang dilakukan oleh penari. Beberapa motif gerak yang ada pada tari Emun Berereng ini merupakan gerak wantah yang telah dihaluskan menjadi gerak maknawi, seperti gerak bersisu gerakan ini merupakan gerak saat berbisik kemudian dihaluskan menjadi gerak tari yang memiliki makna.

Koreografi tari Emun Berereng terbagi menjadi tiga tahap yaitu tahap pembuka yang dilakukan penari yaitu berkaca selanjutnya isi yang terdiri dari besisu, sesilon, kin tene, dan mumikir kemudian ragam penutup yaitu mulangkah ulak. Gerakan-gerakan tersebut tidak hanya terdapat didalam satu ragam tetapi terdapat pula pada ragam lainnya. Seperti gerak transisi, gerak ini terdapat dalam beberapa ragam peralihan. Pada ragam gerak transisi terdapat Sembilan kali pengulangan. Kostum tari yang dikenakan pada tari Emun Berereng sepang baju kerawang berlengan panjang dan memakai penutup kepala yang telah d kreasikan (jilbab).

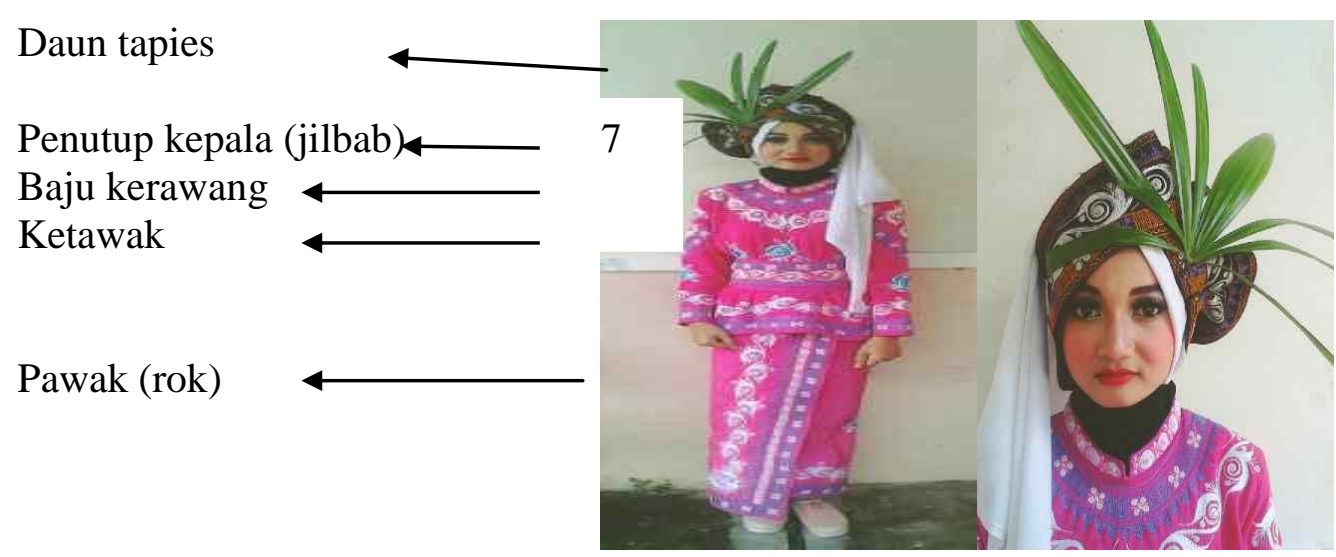

Kostum dan Rias Tari Emun Berereng 


\section{PENUTUP}

Berdasarkan hasil penelitian yang dilakukan di lapangan dan penjelasan yang sudah diuraikan mulai dari latar belakang hingga pembahasan, maka penulis dapat mengambil beberapa kesimpulan dan saran sebagai berikut:

\section{Kesimpulan}

Beberapa hal yang dicatat dan diproleh dari kegiatan menulis dan mendata tentang tari-tari yang ada di daerah Aceh Tengah, salah satunya adalah tari Emun Berereng.

1. Tari Emun Berereng merupakan salah satu tari kreasi dari masyarakat Gayo yang sdidalamnya memiliki unsur keindahan yang diluangkan melalui gerak tubuh penari. Tari Emun Berereng merupakan cerita cinta pada zaman dahulu masyarakta Gayo yang mana pada zaman dulu masyarakat Gayo menjujung adat yang tinggi. Tari Emun Berereng diciptakan pada tahun 1972 oleh seniman Muklis Gayo.

2. Tari Emun Berereng memiliki 13 ragam gerak yaitu bekaca, muningkah suling, besisu, sesilon, mumetik bunge, kin tene, eyop kuyu, muningkah teganing, mudayung, mumikir, muningkah selendang, mungempasi selendang dan mulangkah ulak

3. Koreografi dari tari Emun Berereng memiliki banyak keunikan tersendiri. Diantaranya mengenai desain-desain yang ditimbulkan dari tari tersebut, diantaranya desain atas, desain lantai, desain kelompok, desain dramatik, properti, kostum dan rias, tema dan iringan musik.
4. Tari Emun Berereng menggunakan properti yaitu selendang.




\section{DAFTAR PUSTAKA}

Endaswara, Suwardi. (2006). Metode

, Teori, Teknik Penelitian

Kebudayaan. Slemean :

Pustaka Widyatama

Hadi, Sumandiyo. 2005. Sosiologo

Tari. Yogyakarta: Pustaka

Hadi Y, Sumandiyo, 2007. Kajian

Tari. Yogyakarta : Pustaka

Book Publisher

Hadi Y, Sumandiyo, 2012. Koreografi Bentuk, Isi dan

Teknik". Yogyakarta : Multi Grafindo

Insani, Nurul (2013). Sejarah dan

Bentuk Penyajian Tari Resam

Berume Pada Masyarakat

Gayo Di Aceh Tengah. Skripsi

. Universitas Negeri Medan

Khutniah, Nainul. (2012). Upaya

Mempertahankan Eksistensi

Tari Kridhajati Di Sanggar

Hayu Budaya Kelurahan

Pengkol Kecamatan Jepara.

Jurnal. Universitas Negeri

Semarang

Langer K. Suzanne, 1988. "Problem

Of Art" Terjemahan F.X

Widaryanto

Maryaeni.2005. Metode Penelitian

Kebudayaan . Jakarta: Bumi

Aksara

Saadah (2013). Etika dan Estetika

Tari Guel Pada Masyaarakat

Gayo Kabupaten Aceh

TengahSkripsi. Universitas

Negeri Medan
Smith, Jacqueline (1985), Komposisi

Tari Sebuah Petunjuk Praktis

Bagi Guru, Yogyakarta, Ikalasti Yogyakarta

Soedarsono, 1986. Elemen-Elemen

Dasar Komposisi Tari”,

Yogyakarta : Laligos

Sugiyono. (2010). Metode Penelitian

Kuntitatif dan $R \& D$.

Bandung : Alfabeta

Ulfah, Nazrial. (2011). Keberadan

Dan Perkembangan Tari

Lawuet Pada Masyarakat

Aceh Di Langsa . Skripsi.

Unuversitas Negeri Medan

Ibrahim, Mahmud. (2010). Syariat dan Adat Istiadat Jilid II.

Takengon: yayasan Maqmam Takengon.

http://hermawanmukti.blogspot.com/ 2013/03/mengenal-suku-

gayo.html

Soedarsono $\quad(1976: \quad 26-27)=$

Soedarsono. 1978. Pengantar

Pengetahuan Komposisi Tari.

Yogyakarta.

ASTI.(Soedarsono, R.M.

Pengantar Pengetahuan

Komposisi Tari

Meri, La. 1975. Komposisi

Tari: Elemen-elemen Dasar

Tari. Terj. Soedarsono.

Yogyakarta: ASTI

Sedyawati, Edi. 1986, Pengetahuan

Elemen-elemen Tari dab

beberapa masalah Tari 